(c) VSU, Leyte, Philippines

\title{
The Rising Carbon Footprint of Philippine Households: An Estimation Using Consumption Expenditure and Input-Output Analysis
}

\author{
Moises Neil V. Seriño $0^{1,2}$ \\ ${ }^{1}$ Chair of Development Economics, Göttingen University, Göttingen, Germany and \\ ${ }^{2}$ Department of Economics, Visayas State University, Leyte, Philippines
}

\section{ABSTRACT}

This study aimed to estimate the carbon footprint of Philippine households from consuming various goods and services. Data from the Philippine Input-Output Table and Global Trade Analysis Project's carbon emission coefficients were used to extract the carbon intensities of different economic sectors. The embodied carbon emission from different consumption items was estimated by tracing the associated emission down to its intermediate inputs used in the production. The total household carbon footprint was derived by summing up the carbon emission from each consumption category. Results showed that the highest carbon emitting goods consumed by households are related to expenditure on fuel, light and transportation while nondurable and recreation goods were the least carbon intensive. Different socio-economic characteristics of the households matter in explaining total household carbon footprint. By using non-parametric estimation, results showed a strong positive relationship between household carbon footprint and income but the effect varies across the distribution. This implies that further increases in carbon footprint are to be expected as households get richer. Policy makers should devise policies promoting green consumption or low-carbon lifestyle; else it is likely that households will be leading a carbon intensive lifestyle as they become more affluent.

Keywords: carbon emission, input-output, household consumption, Environmental Kuznets Curve

\section{INTRODUCTION}

There is a consensus among scientists that climate change is attributed to the rising emissions of greenhouse gases (GHG). In its latest assessment report, the Intergovernmental Panel for Climate Change (IPCC) said that it is extremely likely that human influence has been the dominant cause of the observed warming since the mid-20 $0^{\text {th }}$ century (IPCC 2013). Historically, developed countries are responsible for the majority of the

Correspondence: Moises Neil V. Seriño Address: Department of Economics, Visayas State University, Visca, Baybay City, Leyte, Philippines.Email:moisesneil.serino@vsu.edu.ph DOI: $10.32945 /$ atr3821.2016 
accumulated greenhouse gas emissions in the atmosphere. However, in the last decade, greater share of the increase in global carbon dioxide $\left(\mathrm{CO}_{2}\right)$ emissions has come from developing countries, notably from China and other large developing countries. From 2005 onwards and for the first time in history, the aggregate $\mathrm{CO}_{2}$ emissions coming from developing countries surpassed that of the developed countries (International Energy Agency [IEA] 2013). If other developing countries will follow this carbon intensive development pathway, it will further aggravate the alarming concentration of $\mathrm{CO}_{2}$ emissions in the atmosphere and jeopardize the efforts in stabilizing the climate system.

Developing countries are more likely to be affected by the perpetual adverse effects of climate change. According to the climate risk index (CRI) developed by Germanwatch, less developed countries are more frequently hit by extreme weather events and are generally more affected than developed countries (Germanwatch, 2014). The Philippines, being an archipelago, is vulnerable to the adverse effects of climate change. Increases in sea level will affect low lying islands and will displace people. In addition being situated in the Pacific, it will have to endure the effects of stronger typhoons, flooding, drought and other climate disturbances. These would have tremendous effect on the Philippine economy where more than a quarter $(26.5 \%)$ of its population lives below poverty line (NSCB, 2009). Given all these threats, the Philippines has to be actively involved in mitigating climate change. Thus, there is a need to change what has been done in the past and to redefine how things will be done in the present and in the future to deescalate anthropogenic climatic perturbations. This can be potentially done by reducing carbon emissions from production of goods and services.

The Philippines, being one of the countries which ratified the convention on climate change, is required to report its national greenhouse gas inventory as stipulated by the IPCC guidelines. The 1994 national greenhouse gas inventory reports that the Philippines released a total amount of 100,738 ktons of carbon dioxide $\mathrm{CO}_{2}$ into the atmosphere from the combined sector of energy, industry, agriculture and wastes and the net uptake of green house gases from the land use change and forestry sector ("The Philippines Initial National Communication on Climate Change," 1999). However, less has been known on the household side. Households directly or indirectly contribute to the rise of $\mathrm{CO}_{2}$ emission from the consumption of various goods and services. Girod and De Haan (2010) stated that households exert an important influence on total greenhouse gas (GHG) emissions and that their consumption behavior is of interest in evaluations of climate policy options and projections of future emission paths.

Based on the aggregation theory, aggregation over households with unequal incomes leads to rising emissions with rising incomes (Heerink et al. 2001). Consumption patterns and household emissions may differ due to differences in characteristics. According to Bin and Dowlatabadi (2005), 
lifestyle is a way of living that influences and is reflected by one's consumption behavior. In their study using the consumer life approach, they reveal that in the US more than $80 \%$ of the energy used and the $\mathrm{CO}_{2}$ emitted are a consequence of consumer demands. Thus, it is relevant to investigate the consumption behavior of households to understand whether they are leading a carbon intensive lifestyle or not. This study attempted to answer the following questions: (i) which sector of the Philippine economy is carbon intensive? (ii) what are the characteristics of household carbon footprint based on socio-economic characteristics?; and (iii) how does carbon footprint changes as households become richer?

Although the Philippine households' carbon footprint may still not be at an alarming level compared to households from developed countries, but as more households are stepping up the economic ladder, household emission will increase at an enormous level and consequently the effect of that to the climate will be potentially catastrophic. If household emissions were left unattended, the accumulated carbon emission from household consumption will jeopardize the global efforts in trying to stabilize the climate system. Hence, it is relevant to estimate household carbon footprint attributed to consumption before its emission level can get worse.

\section{MATERIALS AND METHODS}

As Kenny and Gray (2009) stated that carbon footprint models are increasingly being used to manage personal and household carbon emissions. Kok et al. (2006) described three methods used to calculate the total energy requirements of households, all based on input-output energy analysis. These include (i) input-output energy analysis based on national account, (ii) input-output energy analysis combined with household expenditure data, and (iii) hybrid analysis, input-output analysis combined with process analysis. Of the methods available, this study utilized inputoutput energy analysis combined with household survey data in calculating the cumulative energy intensities of sectors. Minx et al. (2009) provided an overview of how generalized multi-regional input-output models can be used for carbon footprint applications.

The household carbon footprint was estimated from the consumption side. Households release carbon emissions either directly or indirectly from consuming goods and services. Direct emissions come from households' direct use of energy such as electricity, lighting, cooking, heating, fuel for transportation while indirect emissions take into account the embedded carbon emitted from the production of household goods like clothing, appliances, toiletries and other household items. To account for this, the methodology of input-output analysis was used to extract the $\mathrm{CO}_{2}$ intensity capturing both the direct and indirect emissions. These intensities were matched with the household expenditure categories to estimate for the total household carbon footprint. 
This study used the expenditure approach in estimating the embedded carbon emission in the household consumption. According to Kok et al. (2006), this method is convenient in describing and explaining the environmental load of different household types. It is carried out by calculating the cumulative energy intensities of sectors. Figure 1 shows the process flow using the expenditure approach. The emission intensities of each economic sector from the input-output table and the expenditure survey are necessary to derive the emission of goods and services consumed by the households. Since the focus is on the domestic economy, the study assumes a single-region approach in the computation of household carbon footprint. Exported goods are excluded while imported goods are included in accounting for the $\mathrm{CO}_{2}$ emission.

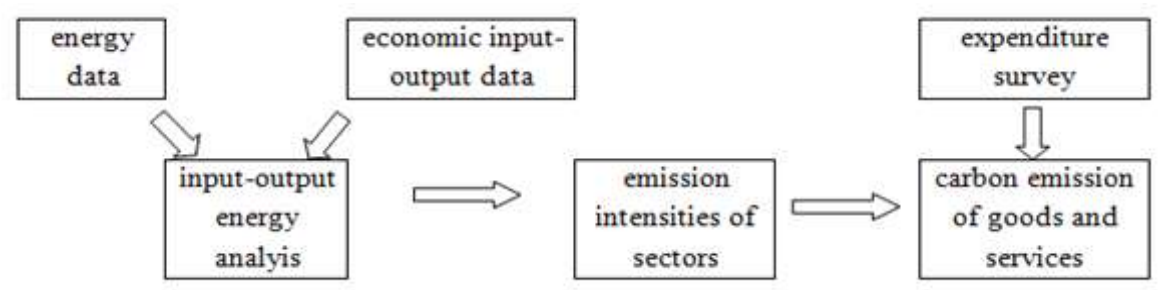

Figure1. Process flow using expenditure approach in estimating household carbon emission Source: Kok etal. (2006).

\section{Estimating household carbon footprint}

Many authors have explored the mechanism of input-output analysis and extended it to investigate environmental issues. Minx et al. (2009) provides a comprehensive literature review on input-output and carbon emissions. The method of input-output was developed by Leontief in 1941 when he studied the relations between economic sectors (Leontief, 1986). The main equation of the input-output analysis is as follows:

$$
X=(I-A)^{-1} y
$$

where $X$ is the vector of total outputs, $A$ is the technological coefficient matrix, $I$ is the unit matrix, and $y$ is the vector of final demand. The equation above is the fundamental representation of input-output analysis and the $(I-A)^{-1}$ matrix is generally known as the Leontief inverse matrix.

To account for the household emission, this study utilized the methods used by Lenzen (1998). Particularly the formula used in this study harbors on the concept of consumer responsibility model (Suh, 2009). Correspondingly, the total $\mathrm{CO}_{2}$ emission from household consumption can be calculated as the sum of indirect $\left(\mathrm{CO}_{2}{ }^{\text {ind }}\right)$ and direct emissions $\left(\mathrm{CO}_{2}^{f d}\right)$.

$$
\mathrm{CO}_{2}=\mathrm{CO}_{2}^{\text {ind }}+\mathrm{CO}_{2}^{f d}(2)
$$


Direct emissions are mainly from the household's direct energy consumption while indirect emissions include all the $\mathrm{CO}_{2}$ emissions emitted from the production of goods and provision of services. The indirect emission $\left(\mathrm{CO}_{2}^{\text {ind }}\right)$, which consists of three components (i) emissions arising from domestic production only (exports are excluded), (ii) emissions arising from imports to intermediate demand and (iii) emissions arising from import of goods and services to final demand, can be calculated by multiplying the transposed emission coefficients $e^{\prime}$ with the industrial energy intensity matrix $E^{\text {ind }}$, as well as the Leontiff inverse (I$A)^{-1}$ and the final demand vector $y$, that is:

$$
C O_{2}^{\text {ind }}=c^{\prime} E^{\text {ind }}\left[(I-A)^{-1} y_{\neq \exp }\left(\left(I-A_{t o t}\right)^{-1}-(I-A)^{-1}\right) y_{\neq \exp }+\left(I-A_{t o t}\right)^{-1} y_{\text {imp }} \quad\right]
$$

where $A_{\text {tot }}=A+A_{\text {imp }}, y_{\text {tot }}=y+y_{\text {imp }}$ and $y_{\text {*exp }}$ is domestic final demand (Suh, 2009). The direct emission arising from final demand can be calculated as follows:

$$
C O_{2}^{f d}=c^{\prime} E^{f d} y
$$

where $E^{f d}$ captures the household's energy use matrix. By putting equations ( 3 ) and (4) together, the total $\mathrm{CO}_{2}$ emission can be accounted as:

$$
C O_{2}^{i n d}=c^{\prime}\left\{E^{\text {ind }}\left[(I-A)^{-1} y_{\neq \exp }\left(\left(I-A_{t o t}\right)^{-1}-(I-A)^{-1}\right) y_{\neq \exp }+\left(I-A_{t o t}\right)^{-1} y_{\text {impt } p_{\text {exp }}}\right]+E^{f d} y\right\}
$$

The carbon footprint of each consumption category was calculated by multiplying (i) the $\mathrm{CO}_{2}$ emission intensity of each individual sector in the economy (derived from equation (5)) and (ii) the corresponding household expenditure category (Cons). Then summing up all the carbon footprint of each consumption categories yields the total carbon footprint for every household, that is:

$$
\mathrm{CO}_{2 i}^{\text {hh }}=\sum_{i}^{j}\left(\mathrm{CO}_{2} * \operatorname{Cons}_{i j}\right)(6)
$$

where $i$ represents the individual household and $j$ the expenditure category.

\section{Sources of Data}

To carry out the estimation of household carbon footprint, three data sets are needed. First, the Philippine Input-Output (IO) table for year 2000 acquired from the National Statistical Coordination Board (NSCB). The 2000 IO table is a matrix of $240 \times 240$ industrial sectors. Second, the Global Trade Analysis Project (GTAP)'s emission intensity data is needed. The 240 IO sectors were mapped with GTAP sectors. Third, data on household expenditure based on the Family Income and Expenditure Survey (FIES) of the National Statistics Office (NSO) is needed. Two rounds of household 
survey (year 2000 and 2006) were used to capture how carbon emission changes with time.

\section{Household expenditure}

To evaluate the composition of household consumption basket in the Philippines, the consumption was disaggregated into 20 major categories. The expenditure in 2006 was deflated using inflation rate to make it comparable with expenditure in 2000. The average annual household expenditure for the year 2000 is US $\$ 2605.28$ while in 2006 the average expenditure increased to US $\$ 2995.34$. There is a huge disparity in average expenditures across income deciles (Figure 2). There is more than fivefold difference in expenditure between the poorest decile $\left(1^{\text {st }}\right)$ and the richest decile $\left(10^{\text {th }}\right)$. Across deciles, expenditures on cereals and root crops do not vary relatively but its share to total expenditure across deciles differs. There is also a noticeable increase in other food items as households get affluent. Expenditure on fruits, vegetables, fish, dairy \& egg and other food remain fairly stable across income quintiles.

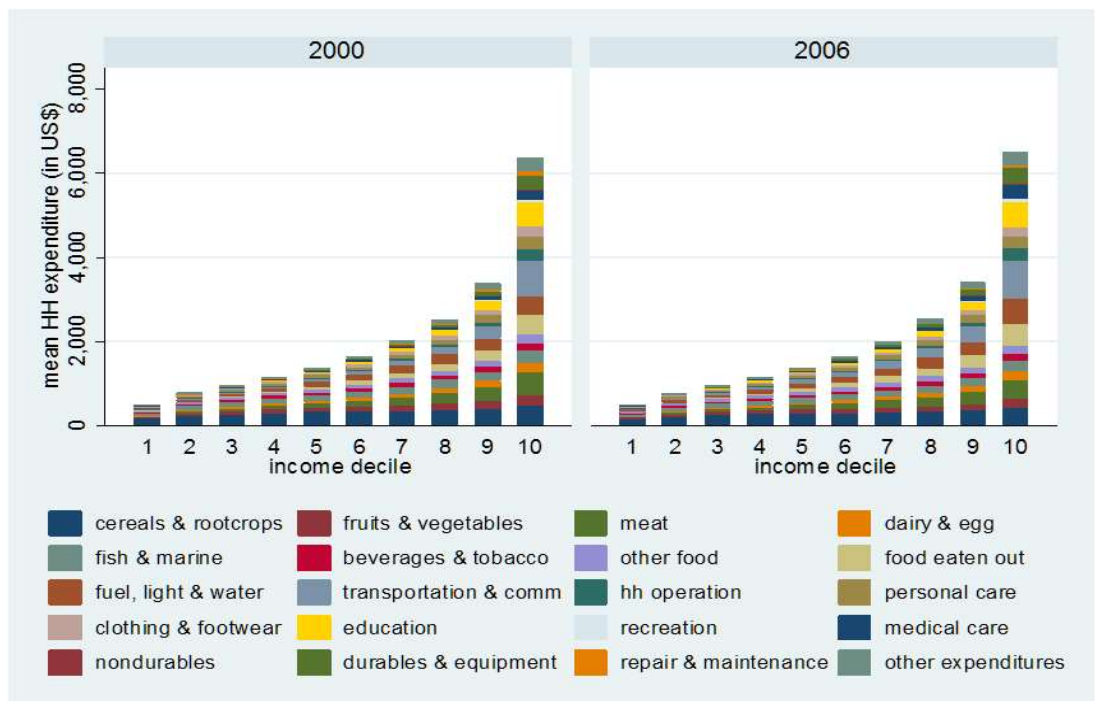

Figure 2. Average expenditure of household by income quintiles, computed based on FIES 2000 and 2006

\section{RESULTS AND DISCUSSION}

\section{Carbon emission intensity of economic sectors}

The results of estimating carbon emission intensity using input-output analysis are presented in Table 1 . The $\mathrm{CO}_{2}$ emission intensity is measured in terms of grams of $\mathrm{CO}_{2}$ per Philippine currency (in peso). This captures the estimated amount of emitted $\mathrm{CO}_{2}$ in the production of goods and services for the year 2000. Most of the sectors which emit $\mathrm{CO}_{2}$ intensively are 
related to energy, travel, mining and manufacturing. The highest carbon emitting sector of the Philippine economy is chromite mining with a carbon intensity of $158.86 \mathrm{gCO}_{2}$ /peso followed closely by the generation of electricity with a carbon intensity of $157.27 \mathrm{gCO}_{2} /$ peso. Conversely, the least carbon intensive sector is the production of other agricultural crops with an estimated intensity of 0.72 grams of $\mathrm{CO}_{2} /$ peso. Most of the least $\mathrm{CO}_{2}$ intensive sectors in the economy include the production of agricultural crops, fruits, vegetables, copra, etc. This is reflective of the real situation because these sectors do not require much energy to produce and this also does not include emissions related to land use change and deforestations. Although there are some manufacturing sectors that have lower $\mathrm{CO}_{2}$ intensity, these sectors only manufacture small and less complicated items.

\section{Characteristics of Household Carbon Footprint}

The emission intensities of economic sectors presented in Table 1 was used in estimating household carbon footprint by matching the sectors with household consumption. After matching the carbon intensity of economic sectors with household consumption, the household carbon footprint was disaggregated into 20 major consumption categories. Table 1 shows the average carbon footprint per major consumption categories measured in terms of tons of $\mathrm{CO}_{2}$ emission. The average $\mathrm{CO}_{2}$ emission varies per consumption item and the most carbon intensive items consumed by households are related to fuel, light followed by transportation. The lowest $\mathrm{CO}_{2}$ emitting items consumed by the households are nondurable goods and recreation. Among food related expenditure, fruits and vegetables have low carbon emission while consumption of meat, dairy and egg consumption show relatively higher carbon emission. This observation is consistent in 2000 and 2006.

Table 1. Mean household $\mathrm{CO}_{2}$ emission by consumption categories (measured in tons)

\begin{tabular}{lcccc}
\hline \multirow{2}{*}{ Consumption Categories } & \multicolumn{2}{c}{2000} & \multicolumn{2}{c}{2006} \\
& Mean & S.D. & Mean & S.D. \\
\hline Cereals \& root crops & 0.060 & 0.0360 & 0.063 & 0.0375 \\
Fruits \& vegetables & 0.013 & 0.0116 & 0.013 & 0.0104 \\
Meat, dairy \& egg & 0.088 & 0.0940 & 0.093 & 0.1016 \\
Fish \& marine goods & 0.074 & 0.0554 & 0.077 & 0.0526 \\
Other food & 0.053 & 0.0410 & 0.060 & 0.0466 \\
Beverages \& tobacco & 0.045 & 0.0519 & 0.047 & 0.0497 \\
Household operation & 0.021 & 0.2232 & 0.029 & 0.3686 \\
Personal care & 0.042 & 0.0476 & 0.049 & 0.0511 \\
Water & 0.062 & 0.1141 & 0.081 & 0.1542 \\
Fuel \& light & 0.627 & 1.1656 & 0.847 & 1.2873 \\
Transportation & 0.223 & 0.3993 & 0.301 & 0.5728 \\
Communication & 0.007 & 0.0230 & 0.011 & 0.0257 \\
Clothing, footwear, etc. & 0.026 & 0.0402 & 0.026 & 0.0418 \\
\hline
\end{tabular}


Table 1. Continuation

\begin{tabular}{lcccc}
\multicolumn{1}{c}{ Consumption Categories } & \multicolumn{2}{c}{2000} & \multicolumn{2}{c}{2006} \\
& Mean & S.D. & Mean & S.D. \\
\hline Education & 0.041 & 0.1157 & 0.048 & 0.1429 \\
Recreation & 0.003 & 0.0117 & 0.003 & 0.0252 \\
Medical care & 0.027 & 0.1519 & 0.043 & 0.2421 \\
Nondurables & 0.003 & 0.0104 & 0.002 & 0.0109 \\
Durables \& equipment & 0.018 & 0.1310 & 0.027 & 0.2089 \\
Repair \& maintenance & 0.008 & 0.0586 & 0.006 & 0.0513 \\
Other expenditure & 0.018 & 0.0713 & 0.020 & 0.1179 \\
\hline Total household emission & 1.465 & 1.8811 & 1.856 & 2.3251 \\
\hline
\end{tabular}

Note. Total number of households in 2000 is 37,766 and in 200638,483 households.

Table 1 also shows that the average carbon footprint in 2006 is higher than the level of emission in 2000. On average, the household carbon footprint for 2000 amounted to 1.465 tons while in 2006, the average household carbon footprint was 1.856 tons. Most noticeable increase was the emission coming from fuel and light. In 2000, the average household emission for fuel and light amounted to 0.627 tons while in 2006 it increased to 0.847 tons. Transportation also shows a noticeable increase while the rest of household consumption items have very marginal increase in their emission levels. Overall, the increase in household carbon emission can be attributed mainly to the increase in emission from fuel, light and transportation.

To evaluate the differences in household emission across income levels, households were divided by income decile and their average carbon emission was compared (Figure 3). The poorest 10 percent of the household are in $1^{\text {st }}$ decile and the richest 10 percent of the households are in the $10^{\text {th }}$ decile. Results show that the there is a gradual increase in the level of emission from the lowest decile to the $9^{\text {th }}$ income decile while there is a huge increase in carbon emission from the $9^{\text {th }}$ decile to the $10^{\text {th }}$ income decile. The households in the richest decile show that their consumption behavior is very carbon intensive relative to the rest. Comparing across year, increase in emission was observed across deciles but the $10^{\text {th }}$ decile posted the largest increase in emission. This implies that a greater portion of the overall increase in household emission is driven mainly by the increase in emission from the richest households. Across income deciles, results show that consistently emission from fuel, light and transportation occupies a greater share to total household emission. The emission from fuel, light and transportation increases as households gets richer. This shows that as household gets richer, their consumption basket tends to be emission intensive.

There is a huge disparity in carbon emissions between households situated in urban and rural areas. Figure 4 shows that on average, urban households emit double the amount of $\mathrm{CO}_{2}$ emitted by the rural households. The average $\mathrm{CO}_{2}$ emitted by the urban households in 2000 is 1.94 tons while rural households emitted 0.77 tons of $\mathrm{Co}_{2}$. In 2006, urban 
households emitted on average 2.83 tons while rural households emitted 1.06 tons. This is reflected by the findings of Seriño (2015) indicating a worsening emission inequality in the Philippines. When comparing emissions from fuel and light, the urban households emitted twice the amount of $\mathrm{CO}_{2}$ emitted by the rural households. The same observation holds true for the emission on transportation. This is because households in the rural areas are mostly out of the energy system. Hence, their level of emission is lower than what is observed in urban areas. Urban households have better access to electricity and transportation pushing their overall emission to increase. So if policy makers are keen in reducing household $\mathrm{CO}_{2}$ emission, focusing on urban households will be a strategic approach.

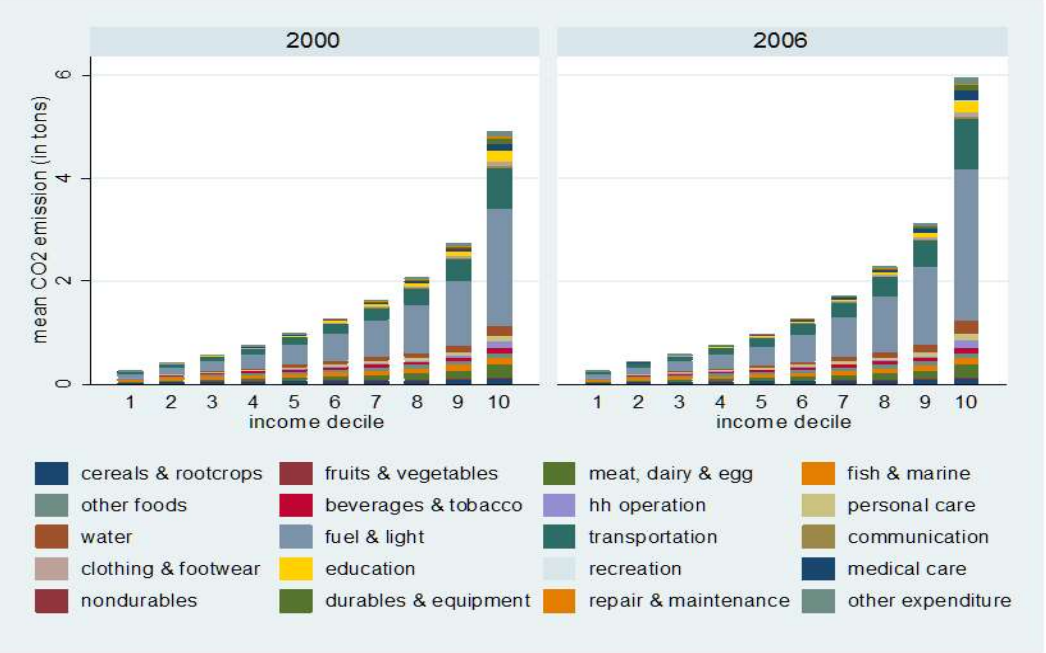

Figure 3. Mean household $\mathrm{CO}_{2}$ emission by income deciles

Previous studies showed that educational attainment is one of the important determinants of household carbon emission (Baiocchi et al. 2010; Buchs and Schnepf, 2013). To account for this, household were aggregated into four major classifications based on education; (i) households having no formal education, (ii) elementary level, (iii) high school and (iv) at least some college education. As shown in Figure 5, as household heads get more educated carbon emission tends to increase. With better education, household heads have better chances of finding employment leading to higher income. In year 2000 , households headed by someone without a formal education emitted around 0.52 tons while households headed by someone who is at least at the college level had carbon emission amounting to as much as 2.75 tons. In year 2006, the average carbon emission across educational attainment has increased. Households headed by someone without formal education emitted 0.59 tons while at least college educated headed households emitted 3.64 tons. Highly educated households seem to be consuming items which are very carbon intensive. This observation is highly correlated with income. 
College or university education in the Philippines is usually a privilege for the rich households. That is why the level of emission of households with at least college level education is relatively high.

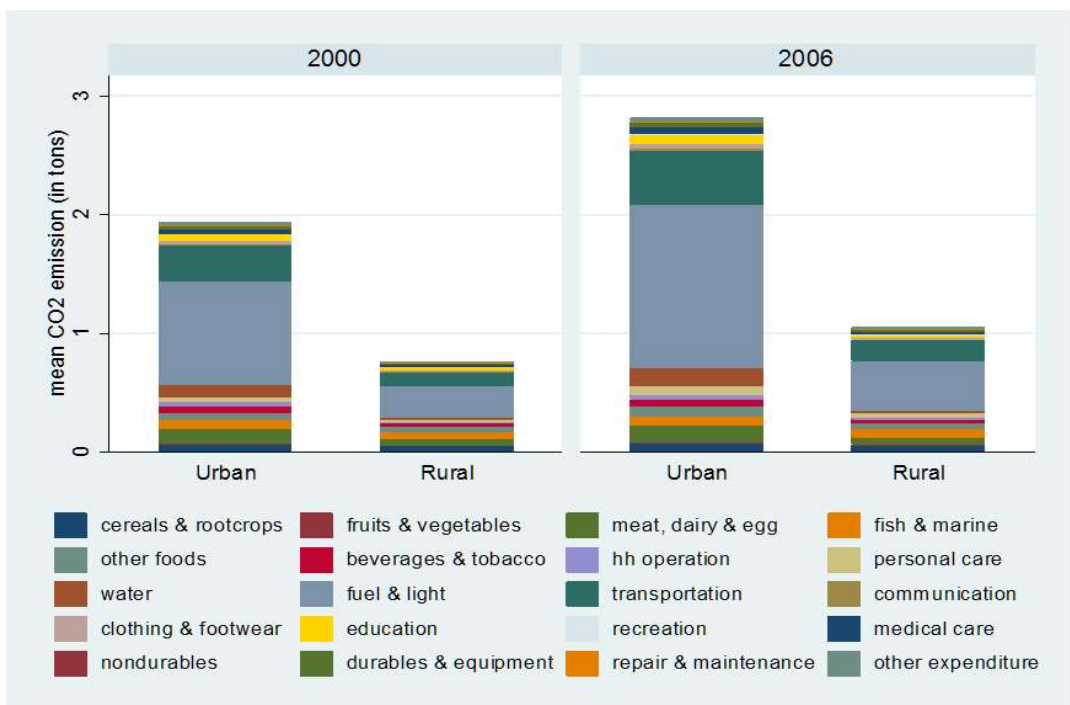

Figure 4. Mean household $\mathrm{CO}_{2}$ emission by urban-rural location

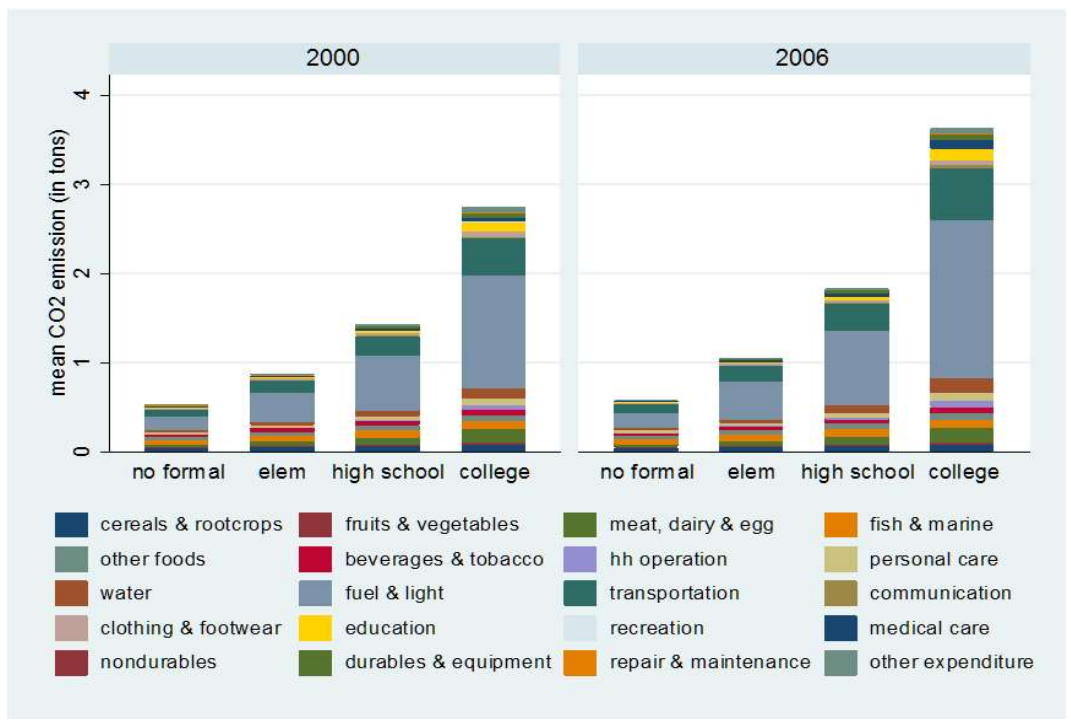

Figure 5. Mean household $\mathrm{CO}_{2}$ emission by educational attainment of household head

A bigger family on average has a higher carbon emission than a smaller one. The average household size in 2000 is 5.2 while in 2006 the average household size is 4.9. Although there is a decrease in household size, the emission across household size increases. The behavior of emission varies across different level of household size. At smaller household size, 
emission tends to increase sharply and then stabilizes from around 4 to 8 members and then again an increase in emission is observed starting from more than 9 members (Figure 6). The decline in the marginal increase of household emission as more members are added into the household captures the economy of scale. Typically, households with more members do share resources hence the marginal increase in emission declines. Under the same roof household members share resources. For example electricity, transport, and housing is shared among household members but on the aggregate still an additional member increases the total household carbon emission.

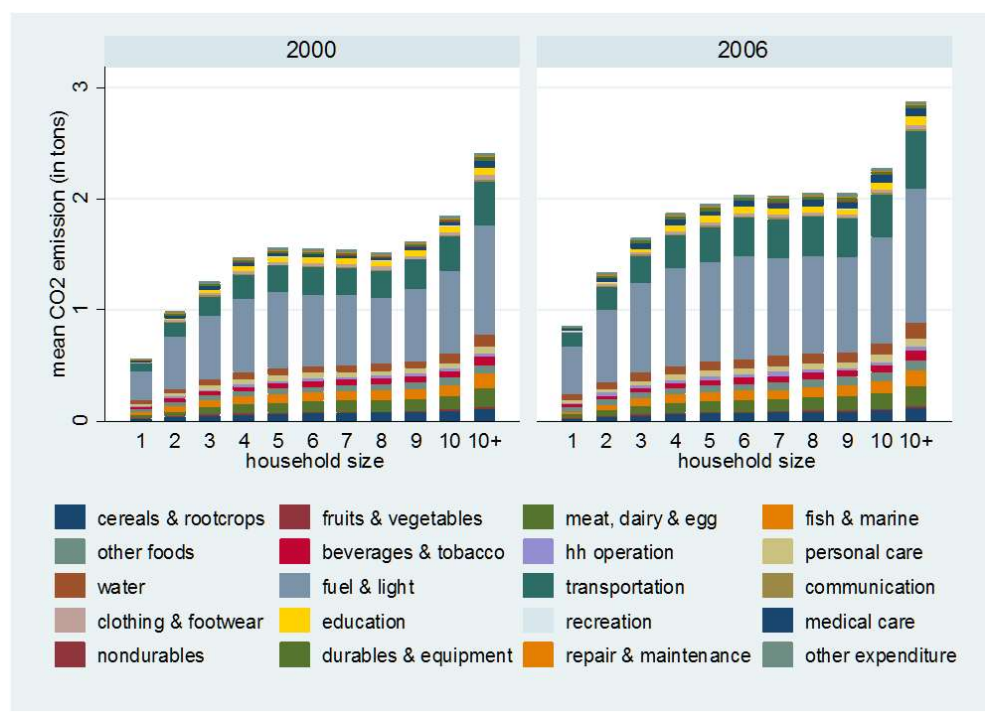

Figure 6. Mean household $\mathrm{CO}_{2}$ emission by household size

Another relevant household characteristic that explains the variation in carbon emission is the age of household head. Preferences, consumption or household structure changes as households get older. Figure 7 shows the comparison of household carbon emission by age of household heads. Figure 7 depicts an inverse U-shaped kind of relationship between age and carbon emission. Household emission increases as the head gets older, reaches its peak and then starts to decline. This captures the changing preferences of households in consumption as they get older. This also reflects the situation where older households are more inclined to consume service-oriented goods which are less carbon intensive as compared to younger households who are just starting to build their families and tend to accumulate more household possessions. The lifestyle of older households is not anymore carbon intensive. The decline in emission of the oldest group is fueled by the decrease in emission from fuel, light and transportation. This observation is consistent in 2000 and 2006.

Comparing the estimation results with other studies, the current findings show that the emission per households in the Philippines is 
relatively small as compared to household emissions in the UK or USA. In UK, the estimated emission is 21.5 tons of carbon per household (Druckman and Jackson, 2009) while in USA, households on the average emit around 50 tons of carbon per household (Weber and Matthews, 2008). Considering economic status of UK and USA as compared to the Philippines, there is a reason to believe that the estimation is reflective of what the Philippine households emit based on their consumption.

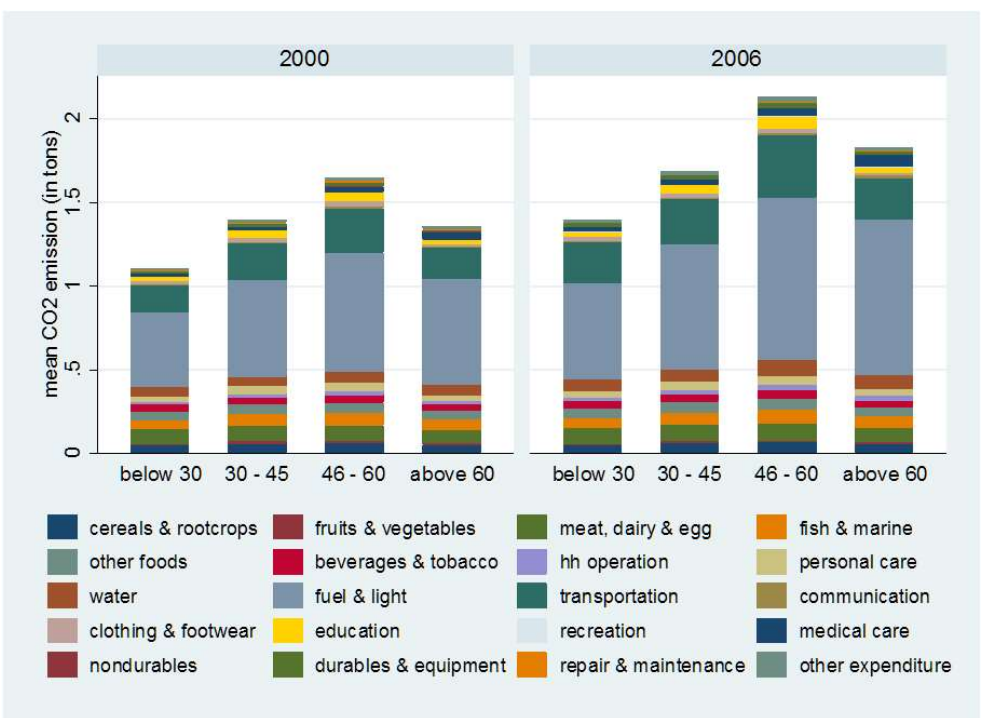

Figure 7. Mean household $\mathrm{CO}_{2}$ emission by age

\section{Household emission and income relationship}

To capture the relationship between household emission and income, the methods of nonparametric estimation was used. With this approach, the functional relationship between emission and income whether it is linear, quadratic or cubic need not be specified. Let the data speak for itself instead of doing trial and error estimation. Nonparametric results provide a graphical overview of the underlying relationship between emission and income and will facilitate parametric estimation. Somehow, the disadvantage of this approach given its bivariate in nature is that it fails to address omitted variable problem and endogeneity issues. Nevertheless, result of this estimation provides a graphical representation of the relationship between two variables by not assuming any predetermined functional form (Padilla and Serrano, 2006).

To document possible changes in the relationship with time, a separate nonparametric estimation between year 2000 and 2006 was conducted. The graph includes the scatter plot between income and emission (Figure 8). The line is the estimated relationship between income and emission and the shaded part is the confidence interval for the estimates. 
For both years, results show that households in the lower income bracket consistently reveal a positive relationship between emission and income. This indicates that an increase in income among poor households is associated with an increase in emission. This result is corroborates with the findings of Seriño (2014) suggesting that income is positively associated with emission using decomposition analysis. However, among households with higher income, the relationship between emission and income is a bit erratic and a clean trend is not evident. For example in 2000, as household income approaches 50,000 US\$ emission tends to shoot up then followed by a steep decline. However in 2006, roughly around 30,000 US\$ income level, emission greatly increases then followed by a steep decline as it gets closer to 50,000 US\$ and then followed by a series of up and down trend. But even though some part in the distribution, emission tends to decline as income increases in 2006, still overall a positive relationship between emission and income is evident.

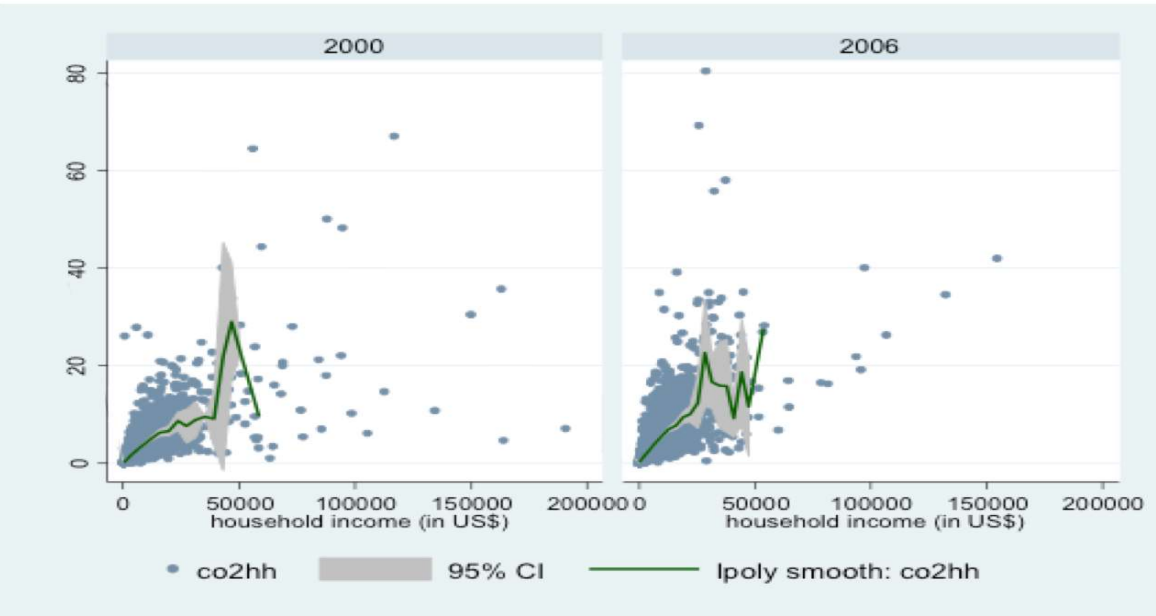

Figure 8. Nonparametric estimation of the associated relation between household income and carbon emission disaggregated by year

At first sight in 2000, the decline in emission as households get richer might be an indication of environmental Kuznets curve (EKC). The EKC hypothesizes that for a given society, environmental problems will increase as income increases up to a point where a further increase in income will lead to a reduction in environmental problems. This is because of greater environmental concern, change of production structure and development of environmental friendly technologies. This means that a growing economy is good for the environment in the long run. However, mounting evidence in the literature shows that EKC is nonexistent and that environmental problems increase with income and no turning point is evident (see for example Stern, 2004; Lenzen et al. 2006; Galeotti et al. 2009). Result in Figure 8 is an indication of a potential presence of EKC in the Philippine setting. This result is complemented by the study conducted by Seriño \& Klasen (2015) where a nonlinear relationship between income 
and emission is confirmed depicting an inverted U-shaped.

The non-parametric estimation of the relationship between emission and income at the household level is consistent with the findings of Padilla and Serrano (2006). They used non-parametric estimation in analyzing the relationship between $\mathrm{CO}_{2}$ emissions and per capita income of different countries pooling all observation from 1971 to 1999. Result shows that higher income is associated with higher emission.

\section{CONCLUSION}

The main objective of this paper is to provide an estimation of the household carbon footprint in the Philippines and investigate how carbon footprint differs across relevant households' socio-economic characteristics. The matching of household consumption items to inputoutput sectors shows that fuel, light, and transportation expenditure are the most carbon intensive goods households consume while nondurable goods and recreation are the least carbon intensive. This observation is consistent in both urban and rural households. Other relevant household characteristics such as household size, age of household head and education matters in describing the behavior of household carbon emission. There is a huge difference in the carbon emission between households in the poorest decile and richest decile. For targeting purposes in curbing emissions, policy makers should focus their attention on households from the richest quintile. Results show that as households get affluent their level of emission also increases. This is further supported by the evidence presented in the non-parametric analysis. It reveals a clear increasing trend between income and carbon footprint among households in the lower income range. For the richer households, the relationship is a bit erratic but overall still indicates that an increase in household income is associated with increase in carbon footprint.

This paper presents a non-parametric estimation, and the results of the study are relevant in describing the behavior of emission from the Philippine households. This sheds some light on the issue related to carbon emissions from developing countries which are less understood in the literature but are heavily affected by the adverse effect of climate change. While developed countries bear a heavy burden in stabilizing the level of emission, active participation from developing country is necessary. According to Heil \& Wodon (1997), everyone regardless of income level must help preserve environmental quality and this is also true for the issue of climate change. While the level of Philippine household carbon footprint is not that worrisome, but the trend is directed towards increasing emission as households get more affluent. Decisions as to what household will consume is rather a private issue but if households are keen in reducing carbon emission they should evaluate their expenditure related to fuel, light and transportation. 


\section{ACKNOWLEDGMENT}

The author acknowledges the financial support from EXPERTS I Erasmus Mundus Partnership in South and South-East Asia, EntdeKen project and the supervision of Prof Stephan Klasen. The author would also like to thank the anonymous referees and editor for their helpful comments and suggestions. All remaining errors are mine.

\section{REFERENCES}

BAIOCCHI, G., J. MINX, J., and K. HUBACEK. 2010. The impact of social factors and consumer behavior on carbon dioxide emissions in the United Kingdom. Journal of Industrial Ecology 14, 50-72.

BIN, S., and H. DOWLATABADI. 2005. Consumer lifestyle approach to US energy use and the related CO2 emissions. Energy Policy 33, 197-208.

BÜCHS, M., and S. SCHNEPF. 2013. Who emits most? Associations between socio-economic factors and UK households' home energy, transport, indirect and total Co2 emissions. Ecological Economics 90: 114-23.

DRUCKMAN, A., and T. JACKSON. 2009. The carbon footprint of UK households 1990-2004: A socio-economically disaggregated, quasimulti-regional input-output model. Ecological Economics 68, 2066-2077.

GALEOTTI, M., M. MANERA and A. LANZA. 2009. On the robustness of robustness checks of the environmental Kuznets curve hypothesis. Environ Resource Economics 42, 551-574.

GERMANWATCH. 2014 . Global climate risk index. http://germanwatch.org/en/cri (accessed 6.23.14).

GIROD, B., and P. DE HAAN. 2010. More or better? A model for changes in household greenhouse gas emissions due to higher income. Journal of Industrial Ecology 14:31-49.

HEERINK, N., A. MULATU, and E. BULTE. 2001. Income inequality and the environment: Aggregation bias in environmental Kuznets curves. Ecological Economics 38, 359-367.

HEIL, M.T., and Q.T. WODON. 1997. Inequality in $\mathrm{CO}_{2}$ emissions between poor and rich countries. The Journal of Environment and Development 6 (4), 426-452.

IEA. 2013. International Energy Agency (IEA): $\mathrm{CO}_{2}$ emissions from fuel combustion.

IPCC. 2013. Intergovernmental panel on Climate Change (IPCC) Press Release - Human influence on climate clear http://www.ipcc.ch/news_and_events/docs/ar5/press_ release_ar5_wgi_en.pdf (accessed 6.23.14).

KENNY, T., and N.F. GRAY. 2009. Comparative performance of six carbon footprint models for use in Ireland. Environmental Impact Assessment Review 29: 1-6. 
KOK, R., R.M.J. BENDERS, and H.C. MOLL. 2006. Measuring the environmental load of household consumption using some methods based on input-output energy analysis: A comparison of methods and a discussion of results. Energy Policy 34, 2744-2761.

LENZEN, M. 1998. Energy and greenhouse gas cost of living for Australia during 1993/94. Energy 23, 497-516.

LENZEN, M., M. WIER, C. COHEN, H. HAYAMI, S. PACHAURI, and R. SCHAEFFER. 2006. A comparative multivariate analysis of household energy requirements in Australia, Brazil, Denmark, India and Japan. Energy 31, 181-207.

LEONTIEF, W. 1986. Input-Output Economics, $2^{\text {nd }}$ ed. New York, Oxford University Press.

MINX, J.C., T. WIEDMANN, R. WOOD, G.P. PETERS, M. LENZEN, A. OWEN, K. SCOTT, J. BARRETT, K. HUBACEK, G. BAIOCCHI, A. PAUL, E. DAWKINS, J. BRIGGS, D. GUAN, S. SUH, and F. ACKERMAN. 2009. Input-output analysis and carbon footprinting: An overview of applications. Economic Systems Research 21:187-216.

NSCB. 2009. National Statistical Coordination Board. Philippine poverty statistics. http://www.nscb.gov.ph/poverty/2009/default.asp

PADILLA, E., and A. SERRANO. 2006. Inequality in $\mathrm{CO}_{2}$ emissions across countries and its relationship with income inequality: A distributive approach.Energy Policy 34: 1762-1772.

SERIÑO, M.N.V. 2014. Decomposing drivers of rising household carbon emission in the Philippines. Advance in Economics and Business 2 (1), 22-28.

SERIÑO, M.N.V. 2015. Rising emission inequality among households in the Philippines. Journal of Society and Technology 5, 70-81.

SERIÑO, M.N.V., and S. KLASEN. 2015. Estimation and determinants of the Philippines' household carbon footprint. The Developing Economies 53 (1),44-62.

STERN, D.I. 2004. The rise and fall of the environmental Kuznets curve. World Development 32, 1419-1439.

SUH, S. 2009. Handbook of input-output analysis Economics in Industrial Ecology. Springer.

The Philippines' Initial National Communication on Climate Change. 1999. http://unfccc.int/resource/ docs/natc/phinc1.pdf

WEBER, C., and S. MATTHEWS. 2008. Quantifying the global and distributional aspects of American household carbon footprint. Ecological Economics 66, 379-391. 